\title{
Hybrid Projection Algorithms for Generalized Equilibrium Problems and Strictly Pseudocontractive Mappings
}

\author{
Jong Kyu Kim, ${ }^{1}$ Sun Young Cho, ${ }^{2}$ and Xiaolong Qin ${ }^{3}$ \\ ${ }^{1}$ Department of Mathematics Education, Kyungnam University, Masan 631-701, Republic of Korea \\ 2 Department of Mathematics, Gyeongsang National University, Chinju 660-701, Republic of Korea \\ ${ }^{3}$ Department of Mathematics, Hangzhou Normal University, Hangzhou 310036, China
}

Correspondence should be addressed to Jong Kyu Kim, jongkyuk@kyungnam.ac.kr

Received 12 October 2009; Accepted 19 July 2010

Academic Editor: András Rontó

Copyright (C) 2010 Jong Kyu Kim et al. This is an open access article distributed under the Creative Commons Attribution License, which permits unrestricted use, distribution, and reproduction in any medium, provided the original work is properly cited.

The purpose of this paper is to consider the problem of finding a common element in the solution set of equilibrium problems and in the fixed point set of a strictly pseudocontractive mapping. Strong convergence of the purposed hybrid projection algorithm is obtained in Hilbert spaces.

\section{Introduction and Preliminaries}

Let $H$ be a real Hilbert space with inner product $\langle\cdot, \cdot\rangle$ and norm $\|\cdot\|$. Let $C$ be a nonempty closed convex subset of $H$ and $S: C \rightarrow C$ a nonlinear mapping. In this paper, we use $F(S)$ to denote the fixed point set of $S$. Recall that the mapping $S$ is said to be nonexpansive if

$$
\|S x-S y\| \leq\|x-y\|, \quad \forall x, y \in C .
$$

$S$ is said to be $k$-strictly pseudocontractive if there exists a constant $k \in[0,1)$ such that

$$
\|S x-S y\|^{2} \leq\|x-y\|^{2}+k\|(x-S x)-(y-S y)\|^{2}, \quad \forall x, y \in C .
$$

$S$ is said to be pseudocontractive if

$$
\|S x-S y\|^{2} \leq\|x-y\|^{2}+\|(x-S x)-(y-S y)\|^{2}, \quad \forall x, y \in C .
$$


The class of strictly pseudocontractive mappings was introduced by Browder and Petryshyn [1] in 1967. It is easy to see that the class of strictly pseudocontractive mappings falls into the class of nonexpansive mappings and the class of pseudocontractions.

Let $A: C \rightarrow H$ be a mapping. Recall that $A$ is said to be monotone if

$$
\langle A x-A y, x-y\rangle \geq 0, \quad \forall x, y \in C
$$

$A$ is said to be inverse-strongly monotone if there exists a constant $\alpha>0$ such that

$$
\langle A x-A y, x-y\rangle \geq \alpha\|A x-A y\|^{2}, \quad \forall x, y \in C .
$$

Let $F$ be a bifunction of $C \times C$ into $\mathbb{R}$, where $\mathbb{R}$ denotes the set of real numbers and $A: C \rightarrow H$ an inverse-strongly monotone mapping. In this paper, we consider the following generalized equilibrium problem.

$$
\text { Find } x \in C \text { such that } F(x, y)+\langle A x, y-x\rangle \geq 0, \quad \forall y \in C \text {. }
$$

In this paper, the set of such an $x \in C$ is denoted by $\operatorname{EP}(F, A)$, that is,

$$
\mathrm{EP}(F, A)=\{x \in C: F(x, y)+\langle A x, y-x\rangle \geq 0, \quad \forall y \in C\}
$$

To study the generalized equilibrium problems (1.6), we may assume that $F$ satisfies the following conditions:

(A1) $F(x, x)=0$ for all $x \in C$;

(A2) $F$ is monotone, that is, $F(x, y)+F(y, x) \leq 0$ for all $x, y \in C$;

(A3) for each $x, y, z \in C$,

$$
\limsup _{t \downarrow 0} F(t z+(1-t) x, y) \leq F(x, y)
$$

(A4) for each $x \in C, y \mapsto F(x, y)$ is convex and weakly lower semicontinuous.

Next, we give two special cases of the problem (1.6).

(I) If $A \equiv 0$, then the generalized equilibrium problem (1.6) is reduced to the following equilibrium problem:

$$
\text { Find } x \in C \text { such that } F(x, y) \geq 0, \quad \forall y \in C \text {. }
$$

In this paper, the set of such an $x \in C$ is denoted by $\mathrm{EP}(F)$, that is,

$$
\mathrm{EP}(F)=\{x \in C: F(x, y) \geq 0, \forall y \in C\}
$$


(II) If $F \equiv 0$, then the problem (1.6) is reduced to the following classical variational inequality. Find $x \in C$ such that

$$
\langle A x, y-x\rangle \geq 0, \quad \forall y \in C
$$

It is known that $x \in C$ is a solution to (1.11) if and only if $x$ is a fixed point of the mapping $P_{C}(I-\rho A)$, where $\rho>0$ is a constant and $I$ is the identity mapping.

Recently, many authors studied the problems (1.6) and (1.9) based on iterative methods; see, for example, [2-18].

In 2007, Tada and Takahashi [17] considered the problem (1.9) and proved the following result.

Theorem TT. Let $C$ be a nonempty closed convex subset of $H$. Let $F$ be a bifunction from $C \times C$ to $\mathbb{R}$ satisfying $(A 1)-(A 4)$ and let $S$ be a nonexpansive mapping of $C$ into $H$ such that $F(S) \cap E P(F) \neq \emptyset$. Let $\left\{x_{n}\right\}$ and $\left\{u_{n}\right\}$ be sequences generated by $x_{1}=x \in H$ and let

$$
\begin{gathered}
F\left(u_{n}, y\right)+\frac{1}{r_{n}}\left\langle y-u_{n}, u_{n}-x_{n}\right\rangle \geq 0, \quad \forall y \in C, \\
w_{n}=\left(1-\alpha_{n}\right) x_{n}+\alpha_{n} S u_{n}, \\
C_{n}=\left\{z \in H:\left\|w_{n}-z\right\| \leq\left\|x_{n}-z\right\|\right\}, \\
D_{n}=\left\{z \in H:\left\langle x_{n}-z, x-x_{n}\right\rangle \geq 0\right\}, \\
x_{n+1}=P_{C_{n} \cap D_{n}} x,
\end{gathered}
$$

for every $n \geq 1$, where $\left\{\alpha_{n}\right\} \subset[a, 1]$ for some $a \in(0,1)$ and $\left\{r_{n}\right\} \subset[0, \infty)$ satisfies $\lim _{\inf } \mathrm{n}_{n \rightarrow \infty} r_{n}>$ 0 . Then, $\left\{x_{n}\right\}$ converges strongly to $P_{F(S) \cap E P(F)} x$.

In this paper, we consider the generalized equilibrium problem (1.6) and a strictly pseudocontractive mapping based on the shrinking projection algorithm which was first introduced by Takahashi et al. [18]. A strong convergence of common elements of the fixed point sets of the strictly pseudocontractive mapping and of the solution sets of the generalized equilibrium problem is established in the framework of Hilbert spaces. The results presented in this paper improve and extend the corresponding results announced by Tada and Takahashi [17].

In order to prove our main results, we also need the following definitions and lemmas.

Lemma 1.1 (see [19]). Let $C$ be a nonempty closed convex subset of a Hilbert space $H$ and $T: C \rightarrow$ $C$ a $k$-strict pseudocontraction. Then $T$ is $(1+k) /(1-k)$-Lipschitz and $I-T$ is demiclosed, this is, if $\left\{x_{n}\right\}$ is a sequence in $C$ with $x_{n} \rightarrow x$ and $x_{n}-T x_{n} \rightarrow 0$, then $x \in F(T)$.

The following lemma can be found in $[2,3]$. 
Lemma 1.2. Let $C$ be a nonempty closed convex subset of $H$ and let $F: C \times C \rightarrow \mathbb{R}$ be a bifunction satisfying $(A 1)-(A 4)$. Then, for any $r>0$ and $x \in H$, there exists $z \in C$ such that

$$
F(z, y)+\frac{1}{r}\langle y-z, z-x\rangle \geq 0, \quad \forall y \in C
$$

Further, define

$$
T_{r} x=\left\{z \in C: F(z, y)+\frac{1}{r}\langle y-z, z-x\rangle \geq 0, \forall y \in C\right\}
$$

for all $r>0$ and $x \in H$. Then, the following hold:

(a) $T_{r}$ is single-valued;

(b) $T_{r}$ is firmly nonexpansive, that is, for any $x, y \in H$,

$$
\left\|T_{r} x-T_{r} y\right\|^{2} \leq\left\langle T_{r} x-T_{r} y, x-y\right\rangle
$$

(c) $F\left(T_{r}\right)=E P(F)$;

(d) $E P(F)$ is closed and convex.

Lemma 1.3 (see [1]). Let $C$ be a nonempty closed convex subset of a real Hilbert space $H$ and $S$ : $C \rightarrow C$ a $k$-strict pseudocontraction with a fixed point. Define $S: C \rightarrow C$ by $S_{a} x=a x+(1-a) S x$ for each $x \in C$. If $a \in[k, 1)$, then $S_{a}$ is nonexpansive with $F\left(S_{a}\right)=F(S)$.

\section{Main Results}

Theorem 2.1. Let $C$ be a nonempty closed convex subset of a real Hilbert space $H$. Let $F_{1}$ and $F_{2}$ be two bifunctions from $C \times C$ to $\mathbb{R}$ which satisfies $(A 1)-(A 4)$. Let $A: C \rightarrow H$ be an $\alpha$-inversestrongly monotone mapping, $B: C \rightarrow H$ a $\beta$-inverse-strongly monotone mapping, and $S: C \rightarrow C$ 
a $k$-strict pseudocontraction. Let $\left\{r_{n}\right\}$ and $\left\{s_{n}\right\}$ be two positive real sequences. Assume that $\mathcal{F}:=$ $\operatorname{EP}\left(F_{1}, A\right) \cap F P\left(F_{2}, B\right) \cap F(S)$ is not empty. Let $\left\{x_{n}\right\}$ be a sequence generated in the following manner:

$$
\begin{gathered}
x_{1} \in C, \\
C_{1}=C, \\
F_{1}\left(u_{n}, u\right)+\left\langle A x_{n}, u-u_{n}\right\rangle+\frac{1}{r_{n}}\left\langle u-u_{n}, u_{n}-x_{n}\right\rangle \geq 0, \quad \forall u \in C, \\
F_{2}\left(v_{n}, v\right)+\left\langle B x_{n}, v-v_{n}\right\rangle+\frac{1}{s_{n}}\left\langle v-v_{n}, v_{n}-x_{n}\right\rangle \geq 0, \quad \forall v \in C, \\
z_{n}=\gamma_{n} u_{n}+\left(1-\gamma_{n}\right) v_{n}, \\
y_{n}=\alpha_{n} x_{n}+\left(1-\alpha_{n}\right)\left(\beta_{n} z_{n}+\left(1-\beta_{n}\right) S z_{n}\right), \\
C_{n+1}=\left\{w \in C_{n}:\left\|y_{n}-w\right\| \leq\left\|x_{n}-w\right\|\right\}, \\
x_{n+1}=P_{C_{n+1}} x_{1}, \quad n \geq 1,
\end{gathered}
$$

where $\left\{\alpha_{n}\right\},\left\{\beta_{n}\right\}$, and $\left\{\gamma_{n}\right\}$ are sequences in $(0,1)$. Assume that $\left\{\alpha_{n}\right\},\left\{\beta_{n}\right\},\left\{\gamma_{n}\right\},\left\{r_{n}\right\}$, and $\left\{s_{n}\right\}$ satisfy the following restrictions:
(a) $0 \leq \alpha_{n} \leq a<1$;
(b) $0 \leq k \leq \beta_{n}<b<1$;
(c) $0 \leq c \leq \gamma_{n} \leq d<1$;
(d) $0<e \leq r_{n} \leq f<2 \alpha$ and $0<e^{\prime} \leq s_{n} \leq f^{\prime}<2 \beta$.

Then the sequence $\left\{x_{n}\right\}$ generated in $(\Upsilon)$ converges strongly to some point $\bar{x}$, where $\bar{x}=P_{\mp} x_{1}$.

Proof. Note that $u_{n}$ can be rewritten as

$$
u_{n}=T_{r_{n}}\left(x_{n}-r_{n} A x_{n}\right), \quad \forall n \geq 1
$$

and $v_{n}$ can be rewritten as

$$
v_{n}=T_{S_{n}}\left(x_{n}-s_{n} B x_{n}\right), \quad \forall n \geq 1 .
$$

Fix $p \in \mathcal{F}$. It follows that

$$
p=S p=T_{r_{n}}\left(p-r_{n} A p\right)=T_{S_{n}}\left(p-s_{n} B p\right), \quad \forall n \geq 1 .
$$


Note that $I-r_{n} A$ is nonexpansive for each $n \geq 1$. Indeed, for any $x, y \in C$, we see from the restriction $(\mathrm{d})$ that

$$
\begin{aligned}
\left\|\left(I-r_{n} A\right) x-\left(I-r_{n} A\right) y\right\|^{2} & =\left\|(x-y)-r_{n}(A x-A y)\right\|^{2} \\
& =\|x-y\|^{2}-2 r_{n}\langle x-y, A x-A y\rangle+r_{n}^{2}\|A x-A y\|^{2} \\
& \leq\|x-y\|^{2}-r_{n}\left(2 \alpha-r_{n}\right)\|A x-A y\|^{2} \\
& \leq\|x-y\|^{2} .
\end{aligned}
$$

This shows that $I-r_{n} A$ is nonexpansive for each $n \geq 1$. In a similar way, we can obtain that $I-s_{n} B$ is nonexpansive for each $n \geq 1$. It follows that

$$
\left\|u_{n}-p\right\| \leq\left\|x_{n}-p\right\|, \quad\left\|u_{n}-p\right\| \leq\left\|x_{n}-p\right\| .
$$

This implies that

$$
\left\|z_{n}-p\right\| \leq \gamma_{n}\left\|u_{n}-p\right\|+\left(1-\gamma_{n}\right)\left\|v_{n}-p\right\| \leq\left\|x_{n}-p\right\|
$$

Now, we are in a position to show that $C_{n}$ is closed and convex for each $n \geq 1$. From the assumption, we see that $C_{1}=C$ is closed and convex. Suppose that $C_{m}$ is closed and convex for some $m \geq 1$. We show that $C_{m+1}$ is closed and convex for the same $m$. Indeed, for any $w \in C_{m}$, we see that

$$
\left\|y_{m}-w\right\| \leq\left\|x_{m}-w\right\|
$$

is equivalent to

$$
\left\|y_{m}\right\|^{2}-\left\|x_{m}\right\|^{2}-2\left\langle w, y_{m}-x_{m}\right\rangle \geq 0
$$

Thus $C_{m+1}$ is closed and convex. This shows that $C_{n}$ is closed and convex for each $n \geq 1$.

Next, we show that $\mp \subset C_{n}$ for each $n \geq 1$. From the assumption, we see that $₹ \subset C=$ $C_{1}$. Suppose that $\mathcal{F} \subset C_{m}$ for some $m \geq 1$. Putting

$$
S_{n}=\beta_{n} I+\left(1-\beta_{n}\right) S, \quad \forall n \geq 1,
$$

we see from Lemma 1.3 that $S_{n}$ is a nonexpansive mapping for each $n \geq 1$. For any $w \in \mathcal{F} \subset$ $C_{m}$, we see from (2.6) that

$$
\begin{aligned}
\left\|y_{m}-w\right\| & =\left\|\alpha_{m} x_{m}+\left(1-\alpha_{m}\right) S_{m} z_{m}-w\right\| \\
& \leq \alpha_{m}\left\|x_{m}-w\right\|+\left(1-\alpha_{m}\right)\left\|z_{m}-w\right\| \\
& \leq\left\|x_{m}-w\right\| .
\end{aligned}
$$


This shows that $w \in C_{m+1}$. This proves that $\mathcal{F} \subset C_{n}$ for each $n \geq 1$. Note $x_{n}=P_{C_{n}} x_{1}$. For each $w \in \mathcal{F} \subset C_{n}$, we have

$$
\left\|x_{1}-x_{n}\right\| \leq\left\|x_{1}-w\right\|
$$

In particular, we have

$$
\left\|x_{1}-x_{n}\right\| \leq\left\|x_{1}-P_{\mp} x_{1}\right\| .
$$

This implies that $\left\{x_{n}\right\}$ is bounded. Since $x_{n}=P_{C_{n}} x_{1}$ and $x_{n+1}=P_{C_{n+1}} x_{1} \in C_{n+1} \subset C_{n}$, we have

$$
\begin{aligned}
0 & \leq\left\langle x_{1}-x_{n}, x_{n}-x_{n+1}\right\rangle \\
& =\left\langle x_{1}-x_{n}, x_{n}-x_{1}+x_{1}-x_{n+1}\right\rangle \\
& \leq-\left\|x_{1}-x_{n}\right\|^{2}+\left\|x_{1}-x_{n}\right\|\left\|x_{1}-x_{n+1}\right\| .
\end{aligned}
$$

It follows that

$$
\left\|x_{n}-x_{1}\right\| \leq\left\|x_{n+1}-x_{1}\right\|
$$

This proves that $\lim _{n \rightarrow \infty}\left\|x_{n}-x_{1}\right\|$ exists. Notice that

$$
\begin{aligned}
\left\|x_{n}-x_{n+1}\right\|^{2} & =\left\|x_{n}-x_{1}+x_{1}-x_{n+1}\right\|^{2} \\
& =\left\|x_{n}-x_{1}\right\|^{2}+2\left\langle x_{n}-x_{1}, x_{1}-x_{n+1}\right\rangle+\left\|x_{1}-x_{n+1}\right\|^{2} \\
& =\left\|x_{n}-x_{1}\right\|^{2}+2\left\langle x_{n}-x_{1}, x_{1}-x_{n}+x_{n}-x_{n+1}\right\rangle+\left\|x_{1}-x_{n+1}\right\|^{2} \\
& =\left\|x_{n}-x_{1}\right\|^{2}-2\left\|x_{n}-x_{1}\right\|^{2}+2\left\langle x_{n}-x_{1}, x_{n}-x_{n+1}\right\rangle+\left\|x_{1}-x_{n+1}\right\|^{2} \\
& \leq\left\|x_{1}-x_{n+1}\right\|^{2}-\left\|x_{n}-x_{1}\right\|^{2} .
\end{aligned}
$$

It follows that

$$
\lim _{n \rightarrow \infty}\left\|x_{n}-x_{n+1}\right\|=0
$$

Since $x_{n+1}=P_{C_{n+1}} x_{1} \in C_{n+1}$, we see that

$$
\left\|y_{n}-x_{n+1}\right\| \leq\left\|x_{n}-x_{n+1}\right\|
$$

This implies that

$$
\left\|y_{n}-x_{n}\right\| \leq\left\|y_{n}-x_{n+1}\right\|+\left\|x_{n}-x_{n+1}\right\| \leq 2\left\|x_{n}-x_{n+1}\right\|
$$


From (2.16), we obtain that

$$
\lim _{n \rightarrow \infty}\left\|x_{n}-y_{n}\right\|=0
$$

On the other hand, we have

$$
\left\|x_{n}-y_{n}\right\|=\left\|x_{n}-\alpha_{n} x_{n}-\left(1-\alpha_{n}\right) S_{n} z_{n}\right\|=\left(1-\alpha_{n}\right)\left\|x_{n}-S_{n} z_{n}\right\| .
$$

From the assumption $0 \leq \alpha_{n} \leq a<1$ and (2.19), we have

$$
\lim _{n \rightarrow \infty}\left\|x_{n}-S_{n} z_{n}\right\|=0
$$

For any $p \in \mathcal{F}$, we have

$$
\begin{aligned}
\left\|u_{n}-p\right\|^{2} & =\left\|T_{r_{n}}\left(I-r_{n} A\right) x_{n}-T_{r_{n}}\left(I-r_{n} A\right) p\right\|^{2} \\
& =\left\|\left(x_{n}-p\right)-r_{n}\left(A x_{n}-A p\right)\right\|^{2} \\
& =\left\|x_{n}-p\right\|^{2}-2 r_{n}\left\langle x_{n}-p, A x_{n}-A p\right\rangle+r_{n}^{2}\left\|A x_{n}-A p\right\|^{2} \\
& \leq\left\|x_{n}-p\right\|^{2}-r_{n}\left(2 \alpha-r_{n}\right)\left\|A x_{n}-A p\right\|^{2} .
\end{aligned}
$$

In a similar way, we also have

$$
\left\|v_{n}-p\right\|^{2} \leq\left\|x_{n}-p\right\|^{2}-s_{n}\left(2 \beta-s_{n}\right)\left\|B x_{n}-B p\right\|^{2} .
$$

Note that

$$
\begin{aligned}
\left\|y_{n}-p\right\|^{2} & =\left\|\alpha_{n} x_{n}+\left(1-\alpha_{n}\right) S_{n} z_{n}-p\right\|^{2} \\
& \leq \alpha_{n}\left\|x_{n}-p\right\|^{2}+\left(1-\alpha_{n}\right)\left\|S_{n} z_{n}-p\right\|^{2} \\
& \leq \alpha_{n}\left\|x_{n}-p\right\|^{2}+\left(1-\alpha_{n}\right)\left\|z_{n}-p\right\|^{2} \\
& \leq \alpha_{n}\left\|x_{n}-p\right\|^{2}+\left(1-\alpha_{n}\right) \gamma_{n}\left\|u_{n}-p\right\|^{2}+\left(1-\alpha_{n}\right)\left(1-\gamma_{n}\right)\left\|v_{n}-p\right\|^{2} .
\end{aligned}
$$

Substituting (2.22) and (2.23) into (2.24), we arrive at

$$
\begin{aligned}
\left\|y_{n}-p\right\|^{2} \leq & \left\|x_{n}-p\right\|^{2}-\left(1-\alpha_{n}\right) \gamma_{n} r_{n}\left(2 \alpha-r_{n}\right)\left\|A x_{n}-A p\right\|^{2} \\
& -\left(1-\alpha_{n}\right)\left(1-\gamma_{n}\right) s_{n}\left(2 \beta-s_{n}\right)\left\|B x_{n}-B p\right\|^{2} .
\end{aligned}
$$


Journal of Inequalities and Applications

It follows that

$$
\begin{aligned}
\left(1-\alpha_{n}\right) \gamma_{n} r_{n}\left(2 \alpha-r_{n}\right)\left\|A x_{n}-A p\right\|^{2} & \leq\left\|x_{n}-p\right\|^{2}-\left\|y_{n}-p\right\|^{2} \\
& \leq\left(\left\|x_{n}-p\right\|+\left\|y_{n}-p\right\|\right)\left\|x_{n}-y_{n}\right\| .
\end{aligned}
$$

In view of the restrictions (a)-(d) and (2.19), we obtain that

$$
\lim _{n \rightarrow \infty}\left\|A x_{n}-A p\right\|=0
$$

It also follows from (2.25) that

$$
\begin{aligned}
\left(1-\alpha_{n}\right)\left(1-\gamma_{n}\right) s_{n}\left(2 \beta-s_{n}\right)\left\|B x_{n}-B p\right\|^{2} & \leq\left\|x_{n}-p\right\|^{2}-\left\|y_{n}-p\right\|^{2} \\
& \leq\left(\left\|x_{n}-p\right\|+\left\|y_{n}-p\right\|\right)\left\|x_{n}-y_{n}\right\| .
\end{aligned}
$$

By virtue of the restrictions (a)-(d) and (2.19), we get that

$$
\lim _{n \rightarrow \infty}\left\|B x_{n}-B p\right\|=0
$$

On the other hand, we have from Lemma 1.1 that

$$
\begin{aligned}
\left\|u_{n}-p\right\|^{2} & =\left\|T_{r_{n}}\left(I-r_{n} A\right) x_{n}-T_{r_{n}}\left(I-r_{n} A\right) p\right\|^{2} \\
& \leq\left\langle\left(I-r_{n} A\right) x_{n}-\left(I-r_{n} A\right) p, u_{n}-p\right\rangle \\
& =\frac{1}{2}\left(\left\|\left(I-r_{n} A\right) x_{n}-\left(I-r_{n} A\right) p\right\|^{2}+\left\|u_{n}-p\right\|^{2}-\left\|\left(I-r_{n} A\right) x_{n}-\left(I-r_{n} A\right) p-\left(u_{n}-p\right)\right\|^{2}\right) \\
& \leq \frac{1}{2}\left(\left\|x_{n}-p\right\|^{2}+\left\|u_{n}-p\right\|^{2}-\left\|x_{n}-u_{n}-r_{n}\left(A x_{n}-A p\right)\right\|^{2}\right) \\
& =\frac{1}{2}\left(\left\|x_{n}-p\right\|^{2}+\left\|u_{n}-p\right\|^{2}-\left(\left\|x_{n}-u_{n}\right\|^{2}-2 r_{n}\left\langle x_{n}-u_{n}, A x_{n}-A p\right\rangle+r_{n}^{2}\left\|A x_{n}-A p\right\|^{2}\right)\right) .
\end{aligned}
$$

This implies that

$$
\left\|u_{n}-p\right\|^{2} \leq\left\|x_{n}-p\right\|^{2}-\left\|x_{n}-u_{n}\right\|^{2}+2 r_{n}\left\|x_{n}-u_{n}\right\|\left\|A x_{n}-A p\right\| .
$$

In a similar way, we can also obtain that

$$
\left\|v_{n}-p\right\|^{2} \leq\left\|x_{n}-p\right\|^{2}-\left\|x_{n}-v_{n}\right\|^{2}+2 s_{n}\left\|x_{n}-v_{n}\right\|\left\|B x_{n}-B p\right\| .
$$


Substituting (2.31) and (2.32) into (2.24), we obtain that

$$
\begin{aligned}
\left\|y_{n}-p\right\|^{2} \leq & \left\|x_{n}-p\right\|^{2}-\left(1-\alpha_{n}\right) \gamma_{n}\left\|x_{n}-u_{n}\right\|^{2}+2 r_{n}\left(1-\alpha_{n}\right) \gamma_{n}\left\|x_{n}-u_{n}\right\|\left\|A x_{n}-A p\right\| \\
& -\left(1-\alpha_{n}\right)\left(1-\gamma_{n}\right)\left\|x_{n}-v_{n}\right\|^{2}+2 s_{n}\left(1-\alpha_{n}\right)\left(1-\gamma_{n}\right)\left\|x_{n}-v_{n}\right\|\left\|B x_{n}-B p\right\| \\
\leq & \left\|x_{n}-p\right\|^{2}-\left(1-\alpha_{n}\right) \gamma_{n}\left\|x_{n}-u_{n}\right\|^{2}+2 r_{n}\left\|x_{n}-u_{n}\right\|\left\|A x_{n}-A p\right\| \\
& -\left(1-\alpha_{n}\right)\left(1-\gamma_{n}\right)\left\|x_{n}-v_{n}\right\|^{2}+2 s_{n}\left\|x_{n}-v_{n}\right\|\left\|B x_{n}-B p\right\| .
\end{aligned}
$$

It follows that

$$
\begin{aligned}
\left(1-\alpha_{n}\right) \gamma_{n}\left\|x_{n}-u_{n}\right\|^{2} \leq & \left\|x_{n}-p\right\|^{2}-\left\|y_{n}-p\right\|^{2}+2 r_{n}\left\|x_{n}-u_{n}\right\|\left\|A x_{n}-A p\right\| \\
& +2 s_{n}\left\|x_{n}-v_{n}\right\|\left\|B x_{n}-B p\right\| \\
\leq & \left(\left\|x_{n}-p\right\|+\left\|y_{n}-p\right\|\right)\left\|x_{n}-y_{n}\right\|+2 r_{n}\left\|x_{n}-u_{n}\right\|\left\|A x_{n}-A p\right\| \\
& +2 s_{n}\left\|x_{n}-v_{n}\right\|\left\|B x_{n}-B p\right\| .
\end{aligned}
$$

In view of the restrictions (a) and (c), we obtain from (2.27) and (2.29) that

$$
\lim _{n \rightarrow \infty}\left\|x_{n}-u_{n}\right\|=0
$$

It also follows from (2.33) that

$$
\begin{aligned}
\left(1-\alpha_{n}\right)\left(1-\gamma_{n}\right)\left\|x_{n}-v_{n}\right\|^{2} \leq & \left\|x_{n}-p\right\|^{2}-\left\|y_{n}-p\right\|^{2}+2 r_{n}\left\|x_{n}-u_{n}\right\|\left\|A x_{n}-A p\right\| \\
& +2 s_{n}\left\|x_{n}-v_{n}\right\|\left\|B x_{n}-B p\right\| \\
\leq & \left(\left\|x_{n}-p\right\|+\left\|y_{n}-p\right\|\right)\left\|x_{n}-y_{n}\right\|+2 r_{n}\left\|x_{n}-u_{n}\right\|\left\|A x_{n}-A p\right\| \\
& +2 s_{n}\left\|x_{n}-v_{n}\right\|\left\|B x_{n}-B p\right\| .
\end{aligned}
$$

Thanks to the restrictions (a) and (c), we obtain from (2.27) and (2.29) that

$$
\lim _{n \rightarrow \infty}\left\|x_{n}-v_{n}\right\|=0
$$

Note that

$$
\left\|z_{n}-x_{n}\right\| \leq \gamma_{n}\left\|u_{n}-x_{n}\right\|+\left(1-\gamma_{n}\right)\left\|v_{n}-x_{n}\right\| .
$$

From (2.35) and (2.37), we see that

$$
\lim _{n \rightarrow \infty}\left\|x_{n}-z_{n}\right\|=0
$$


Journal of Inequalities and Applications

On the other hand, we see from (2.21) that

$$
\beta_{n}\left(z_{n}-x_{n}\right)+\left(1-\beta_{n}\right)\left(S z_{n}-x_{n}\right) \longrightarrow 0
$$

as $n \rightarrow \infty$. In view of (2.39) and the restriction (b), we obtain that

$$
\lim _{n \rightarrow \infty}\left\|x_{n}-S z_{n}\right\|=0
$$

Note that

$$
\left\|S x_{n}-x_{n}\right\| \leq\left\|S x_{n}-S z_{n}\right\|+\left\|S z_{n}-x_{n}\right\| \leq \frac{1+k}{1-k}\left\|x_{n}-z_{n}\right\|+\left\|S z_{n}-x_{n}\right\| .
$$

It follows from (2.39) and (2.41) that

$$
\lim _{n \rightarrow \infty}\left\|x_{n}-S x_{n}\right\|=0
$$

Since $\left\{x_{n}\right\}$ is bounded, we assume that a subsequence $\left\{x_{n_{i}}\right\}$ of $\left\{x_{n}\right\}$ converges weakly to $\xi$.

Next, we show that $\xi \in F(S) \cap \operatorname{EP}\left(F_{1}, A\right) \cap \operatorname{EP}\left(F_{2}, B\right)$. First, we prove that $\xi \in \operatorname{EP}\left(F_{1}, A\right)$. Since $u_{n}=T_{r_{n}}\left(x_{n}-r_{n} A x_{n}\right)$ for any $u \in C$, we have

$$
F_{1}\left(u_{n}, u\right)+\left\langle A x_{n}, u-u_{n}\right\rangle+\frac{1}{r_{n}}\left\langle u-u_{n}, u_{n}-x_{n}\right\rangle \geq 0
$$

From the condition (A2), we see that

$$
\left\langle A x_{n}, u-u_{n}\right\rangle+\frac{1}{r_{n}}\left\langle u-u_{n}, u_{n}-x_{n}\right\rangle \geq F_{1}\left(u, u_{n}\right) .
$$

Replacing $n$ by $n_{i}$, we arrive at

$$
\left\langle A x_{n_{i}}, u-u_{n_{i}}\right\rangle+\left\langle u-u_{n_{i}}, \frac{u_{n_{i}}-x_{n_{i}}}{r_{n_{i}}}\right\rangle \geq F_{1}\left(u, u_{n_{i}}\right) .
$$

For any $t$ with $0<t \leq 1$ and $u \in C$, let $u_{t}=t u+(1-t) \xi$. Since $u \in C$ and $\xi \in C$, we have $u_{t} \in C$. It follows from (2.46) that

$$
\begin{aligned}
\left\langle u_{t}-u_{n_{i}}, A u_{t}\right\rangle & \geq\left\langle u_{t}-u_{n_{i}}, A u_{t}\right\rangle-\left\langle A x_{n_{i}}, u_{t}-u_{n_{i}}\right\rangle-\left\langle u_{t}-u_{n_{i}}, \frac{u_{n_{i}}-x_{n_{i}}}{r_{n_{i}}}\right\rangle+F_{1}\left(u_{t}, u_{n_{i}}\right) \\
& =\left\langle u_{t}-u_{n_{i}}, A u_{t}-A u_{n_{i}}\right\rangle+\left\langle u_{t}-u_{n_{i}}, A u_{n_{i}}-A x_{n_{i}}\right\rangle-\left\langle u_{t}-u_{n_{i}}, \frac{u_{n_{i}}-x_{n_{i}}}{r_{n_{i}}}\right\rangle+F_{1}\left(u_{t}, u_{n_{i}}\right) .
\end{aligned}
$$


Since $A$ is Lipschitz continuous, we obtain from (2.35) that $A u_{n_{i}}-A x_{n_{i}} \rightarrow 0$ as $i \rightarrow \infty$. On the other hand, we get from the monotonicity of $A$ that

$$
\left\langle u_{t}-u_{n_{i}}, A u_{t}-A u_{n_{i}}\right\rangle \geq 0
$$

It follows from (A4) and (2.47) that

$$
\left\langle u_{t}-\xi, A u_{t}\right\rangle \geq F_{1}\left(u_{t}, \xi\right)
$$

From (A1), (A4), and (2.49), we see that

$$
\begin{aligned}
0 & =F_{1}\left(u_{t}, u_{t}\right) \leq t F_{1}\left(u_{t}, u\right)+(1-t) F_{1}\left(u_{t}, \xi\right) \\
& \leq t F_{1}\left(u_{t}, u\right)+(1-t)\left\langle u_{t}-\xi, A u_{t}\right\rangle \\
& =t F_{1}\left(u_{t}, u\right)+(1-t) t\left\langle u-\xi, A u_{t}\right\rangle
\end{aligned}
$$

which yields that

$$
F_{1}\left(u_{t}, u\right)+(1-t)\left\langle u-\xi, A u_{t}\right\rangle \geq 0
$$

Letting $t \rightarrow 0$ in the above inequality, we arrive at

$$
F_{1}(\xi, u)+\langle u-\xi, A \xi\rangle \geq 0
$$

This shows that $\xi \in \operatorname{EP}\left(F_{1}, A\right)$. In a similar way, we can obtain that $\xi \in \operatorname{EP}\left(F_{2}, B\right)$.

Next, we show that $\xi \in F(S)$. We can conclude from Lemma 1.1 the desired conclusion easily. This proves that $\xi \in \mathcal{F}$. Put $\bar{x}=P_{\bar{q}} x_{1}$. Since $\bar{x}=P_{\bar{q}} x_{1} \subset C_{n+1}$ and $x_{n+1}=P_{C_{n+1}} x_{1}$, we have

$$
\left\|x_{1}-x_{n+1}\right\| \leq\left\|x_{1}-\bar{x}\right\|
$$

On the other hand, we have

$$
\begin{aligned}
\left\|x_{1}-\bar{x}\right\| & \leq\left\|x_{1}-\xi\right\| \\
& \leq \liminf _{i \rightarrow \infty}\left\|x_{1}-x_{n_{i}}\right\| \\
& \leq \limsup _{i \rightarrow \infty}\left\|x_{1}-x_{n_{i}}\right\| \\
& \leq\left\|x_{1}-\bar{x}\right\| .
\end{aligned}
$$


We, therefore, obtain that

$$
\left\|x_{1}-\xi\right\|=\lim _{i \rightarrow \infty}\left\|x_{1}-x_{n_{i}}\right\|=\left\|x_{1}-\bar{x}\right\| .
$$

This implies $x_{n_{i}} \rightarrow \xi=\bar{x}$. Since $\left\{x_{n_{i}}\right\}$ is an arbitrary subsequence of $\left\{x_{n}\right\}$, we obtain that $x_{n} \rightarrow \bar{x}$ as $n \rightarrow \infty$. This completes the proof.

If $S$ is nonexpansive, then we have from Theorem 2.1 the following result immediately.

Corollary 2.2. Let $C$ be a nonempty closed convex subset of a real Hilbert space $H$. Let $F_{1}$ and $F_{2}$ be two bifunctions from $C \times C$ to $\mathbb{R}$ which satisfies $(A 1)-(A 4)$. Let $A: C \rightarrow H$ be an $\alpha$ inverse-strongly monotone mapping, $B: C \rightarrow H$ a $\beta$-inverse-strongly monotone mapping, and $S: C \rightarrow C$ a nonexpansive mapping. Let $\left\{r_{n}\right\}$ and $\left\{s_{n}\right\}$ be two positive real sequences. Assume that $F:=E P\left(F_{1}, A\right) \cap F P\left(F_{2}, B\right) \cap F(S)$ is not empty. Let $\left\{x_{n}\right\}$ be a sequence generated in the following manner:

$$
\begin{gathered}
x_{1} \in C, \\
C_{1}=C, \\
F_{1}\left(u_{n}, u\right)+\left\langle A x_{n}, u-u_{n}\right\rangle+\frac{1}{r_{n}}\left\langle u-u_{n}, u_{n}-x_{n}\right\rangle \geq 0, \quad \forall u \in C, \\
F_{2}\left(v_{n}, v\right)+\left\langle B x_{n}, v-v_{n}\right\rangle+\frac{1}{s_{n}}\left\langle v-v_{n}, v_{n}-x_{n}\right\rangle \geq 0, \quad \forall v \in C, \\
y_{n}=\alpha_{n} x_{n}+\left(1-\alpha_{n}\right) S\left(\gamma_{n} u_{n}+\left(1-\gamma_{n}\right) v_{n}\right), \\
C_{n+1}=\left\{w \in C_{n}:\left\|y_{n}-w\right\| \leq\left\|x_{n}-w\right\|\right\}, \\
x_{n+1}=P_{C_{n+1}} x_{1}, \quad n \geq 1,
\end{gathered}
$$

where $\left\{\alpha_{n}\right\}$ and $\left\{\gamma_{n}\right\}$ are sequences in $(0,1)$. Assume that $\left\{\alpha_{n}\right\},\left\{\gamma_{n}\right\},\left\{r_{n}\right\}$, and $\left\{s_{n}\right\}$ satisfy the following restrictions:

(a) $0 \leq \alpha_{n} \leq a<1$;

(b) $0 \leq c \leq \gamma_{n} \leq d<1$;

(c) $0<e \leq r_{n} \leq f<2 \alpha$ and $0<e^{\prime} \leq s_{n} \leq f^{\prime}<2 \beta$.

Then the sequence $\left\{x_{n}\right\}$ converges strongly to some point $\bar{x}$, where $\bar{x}=P_{\bar{q}} x_{1}$.

As applications of Theorem 2.1, we consider the problems (1.9) and (1.11). 
Theorem 2.3. Let $C$ be a nonempty closed convex subset of a real Hilbert space $H$. Let $A: C \rightarrow H$ be an $\alpha$-inverse-strongly monotone mapping, $B: C \rightarrow H$ a $\beta$-inverse-strongly monotone mapping, and $S: C \rightarrow C$ a $k$-strict pseudocontraction. Let $\left\{r_{n}\right\}$ and $\left\{s_{n}\right\}$ be two positive real sequences. Assume that $\mathcal{F}:=\operatorname{VI}(C, A) \cap \operatorname{VI}(C, B) \cap F(S)$ is not empty. Let $\left\{x_{n}\right\}$ be a sequence generated in the following manner:

$$
\begin{gathered}
x_{1} \in C, \\
C_{1}=C \\
z_{n}=\gamma_{n} P_{C}\left(I-r_{n} A\right) x_{n}+\left(1-\gamma_{n}\right) P_{C}\left(I-s_{n} B\right) x_{n}, \\
y_{n}=\alpha_{n} x_{n}+\left(1-\alpha_{n}\right)\left(\beta_{n} z_{n}+\left(1-\beta_{n}\right) S z_{n}\right), \\
C_{n+1}=\left\{w \in C_{n}:\left\|y_{n}-w\right\| \leq\left\|x_{n}-w\right\|\right\}, \\
x_{n+1}=P_{C_{n+1}} x_{1}, \quad n \geq 1,
\end{gathered}
$$

where $\left\{\alpha_{n}\right\},\left\{\beta_{n}\right\}$, and $\left\{\gamma_{n}\right\}$ are sequences in $(0,1)$. Assume that $\left\{\alpha_{n}\right\},\left\{\beta_{n}\right\},\left\{\gamma_{n}\right\},\left\{r_{n}\right\}$, and $\left\{s_{n}\right\}$ satisfy the following restrictions:

(a) $0 \leq \alpha_{n} \leq a<1$;

(b) $0 \leq k \leq \beta_{n}<b<1$;

(c) $0 \leq c \leq \gamma_{n} \leq d<1$;

(d) $0<e \leq r_{n} \leq f<2 \alpha$ and $0<e^{\prime} \leq s_{n} \leq f^{\prime}<2 \beta$.

Then the sequence $\left\{x_{n}\right\}$ converges strongly to some point $\bar{x}$, where $\bar{x}=P_{\bar{q}} x_{1}$.

Proof. Putting $F_{1}=F_{2} \equiv 0$, we see that

$$
\left\langle A x_{n}, u-u_{n}\right\rangle+\frac{1}{r_{n}}\left\langle u-u_{n}, u_{n}-x_{n}\right\rangle \geq 0, \quad \forall u \in C,
$$

is equivalent to

$$
\left\langle x_{n}-r_{n} A x_{n}-u_{n}, u_{n}-u\right\rangle \geq 0, \quad \forall u \in C
$$

This implies that $u_{n}=P_{C}\left(x_{n}-r_{n} A x_{n}\right)$. We also have $v_{n}=P_{C}\left(x_{n}-s_{n} B x_{n}\right)$. We can obtain from Theorem 2.1 the desired results immediately.

Corollary 2.4. Let $C$ be a nonempty closed convex subset of a real Hilbert space $H$. Let $A: C \rightarrow H$ be an $\alpha$-inverse-strongly monotone mapping, $B: C \rightarrow H$ a $\beta$-inverse-strongly monotone mapping, and $S: C \rightarrow C$ a nonexpansive mapping. Let $\left\{r_{n}\right\}$ and $\left\{s_{n}\right\}$ be two positive real sequences. Assume 
that $\mathcal{F}:=V I(C, A) \cap V I(C, B) \cap F(S)$ is not empty. Let $\left\{x_{n}\right\}$ be a sequence generated in the following manner:

$$
\begin{gathered}
x_{1} \in C, \\
C_{1}=C, \\
z_{n}=\gamma_{n} P_{C}\left(I-r_{n} A\right) x_{n}+\left(1-\gamma_{n}\right) P_{C}\left(I-s_{n} B\right) x_{n}, \\
y_{n}=\alpha_{n} x_{n}+\left(1-\alpha_{n}\right) S z_{n}, \\
C_{n+1}=\left\{w \in C_{n}:\left\|y_{n}-w\right\| \leq\left\|x_{n}-w\right\|\right\}, \\
x_{n+1}=P_{C_{n+1}} x_{1}, \quad n \geq 1,
\end{gathered}
$$

where $\left\{\alpha_{n}\right\}$ and $\left\{\gamma_{n}\right\}$ are sequences in $(0,1)$. Assume that $\left\{\alpha_{n}\right\},\left\{\gamma_{n}\right\},\left\{r_{n}\right\}$, and $\left\{s_{n}\right\}$ satisfy the following restrictions:
(a) $0 \leq \alpha_{n} \leq a<1$;
(b) $0 \leq c \leq \gamma_{n} \leq d<1$;
(c) $0<e \leq r_{n} \leq f<2 \alpha$ and $0<e^{\prime} \leq s_{n} \leq f^{\prime}<2 \beta$.

Then the sequence $\left\{x_{n}\right\}$ converges strongly to some point $\bar{x}$, where $\bar{x}=P_{\mp} x_{1}$.

Theorem 2.5. Let $C$ be a nonempty closed convex subset of a real Hilbert space $H$. Let $F_{1}$ and $F_{2}$ be two bifunctions from $C \times C$ to $\mathbb{R}$ which satisfies $(A 1)-(A 4)$. Let $S: C \rightarrow C$ be a $k$ strict pseudocontraction. Let $\left\{r_{n}\right\}$ and $\left\{s_{n}\right\}$ be two positive real sequences. Assume that $\mathcal{F}:=$ $E P\left(F_{1}\right) \cap F P\left(F_{2}\right) \cap F(S)$ is not empty. Let $\left\{x_{n}\right\}$ be a sequence generated in the following manner:

$$
\begin{gathered}
x_{1} \in C, \\
C_{1}=C, \\
F_{1}\left(u_{n}, u\right)+\frac{1}{r_{n}}\left\langle u-u_{n}, u_{n}-x_{n}\right\rangle \geq 0, \quad \forall u \in C, \\
F_{2}\left(v_{n}, v\right)+\frac{1}{s_{n}}\left\langle v-v_{n}, v_{n}-x_{n}\right\rangle \geq 0, \quad \forall v \in C, \\
z_{n}=\gamma_{n} u_{n}+\left(1-\gamma_{n}\right) v_{n}, \\
y_{n}=\alpha_{n} x_{n}+\left(1-\alpha_{n}\right)\left(\beta_{n} z_{n}+\left(1-\beta_{n}\right) S z_{n}\right), \\
C_{n+1}=\left\{w \in C_{n}:\left\|y_{n}-w\right\| \leq\left\|x_{n}-w\right\|\right\}, \\
x_{n+1}=P_{C_{n+1}} x_{1}, \quad n \geq 1,
\end{gathered}
$$

where $\left\{\alpha_{n}\right\},\left\{\beta_{n}\right\}$, and $\left\{\gamma_{n}\right\}$ are sequences in $(0,1)$. Assume that $\left\{\alpha_{n}\right\},\left\{\beta_{n}\right\},\left\{\gamma_{n}\right\},\left\{r_{n}\right\}$, and $\left\{s_{n}\right\}$ satisfy the following restrictions:

(a) $0 \leq \alpha_{n} \leq a<1$;

(b) $0 \leq k \leq \beta_{n}<b<1$; 
(c) $0 \leq c \leq \gamma_{n} \leq d<1$;

(d) $0<e \leq r_{n} \leq f<\infty$ and $0<e^{\prime} \leq s_{n} \leq f^{\prime}<\infty$.

Then the sequence $\left\{x_{n}\right\}$ converges strongly to some point $\bar{x}$, where $\bar{x}=P_{\bar{q}} x_{1}$.

Proof. Putting $A=B=0$, we can obtain from Theorem 2.1 the desired conclusion immediately.

Remark 2.6. Theorem 2.5 is generalization of Theorem TT. To be more precise, we consider a pair of bifunctions and a strictly pseudocontractive mapping.

Let $\mathrm{T}: C \rightarrow C$ be a $k$-strict pseudocontraction. It is known that $I-T$ is a $(1-k) / 2$ inverse-strongly monotone mapping. The following results are not hard to derive.

Theorem 2.7. Let $C$ be a nonempty closed convex subset of a real Hilbert space $H$. Let $F_{1}$ and $F_{2}$ be two bifunctions from $C \times C$ to $\mathbb{R}$ which satisfies $(A 1)-(A 4)$. Let $T_{A}: C \rightarrow C$ be a $k_{\alpha}$-strict pseudocontraction, $B: C \rightarrow C$ a $k_{\beta}$-strict pseudocontraction, and $S: C \rightarrow C$ a $k$-strict pseudocontraction. Let $\left\{r_{n}\right\}$ and $\left\{s_{n}\right\}$ be two positive real sequences. Assume that $\mathcal{F}:=$ $E P\left(F_{1}, I-T_{A}\right) \cap F P\left(F_{2}, I-T_{B}\right) \cap F(S)$ is not empty. Let $\left\{x_{n}\right\}$ be a sequence generated in the following manner:

$$
\begin{gathered}
x_{1} \in C, \\
C_{1}=C, \\
F_{1}\left(u_{n}, u\right)+\left\langle\left(I-T_{A}\right) x_{n}, u-u_{n}\right\rangle+\frac{1}{r_{n}}\left\langle u-u_{n}, u_{n}-x_{n}\right\rangle \geq 0, \quad \forall u \in C, \\
F_{2}\left(v_{n}, v\right)+\left\langle\left(I-T_{B}\right) x_{n}, v-v_{n}\right\rangle+\frac{1}{s_{n}}\left\langle v-v_{n}, v_{n}-x_{n}\right\rangle \geq 0, \quad \forall v \in C, \\
z_{n}=\gamma_{n} u_{n}+\left(1-\gamma_{n}\right) v_{n}, \\
y_{n}=\alpha_{n} x_{n}+\left(1-\alpha_{n}\right)\left(\beta_{n} z_{n}+\left(1-\beta_{n}\right) S z_{n}\right), \\
C_{n+1}=\left\{w \in C_{n}:\left\|y_{n}-w\right\| \leq\left\|x_{n}-w\right\|\right\}, \\
x_{n+1}=P_{C_{n+1}} x_{1}, \quad n \geq 1,
\end{gathered}
$$

where $\left\{\alpha_{n}\right\},\left\{\beta_{n}\right\}$, and $\left\{\gamma_{n}\right\}$ are sequences in $(0,1)$. Assume that $\left\{\alpha_{n}\right\},\left\{\beta_{n}\right\},\left\{\gamma_{n}\right\},\left\{r_{n}\right\}$, and $\left\{s_{n}\right\}$ satisfy the following restrictions:

(a) $0 \leq \alpha_{n} \leq a<1$;

(b) $0 \leq k \leq \beta_{n}<b<1$;

(c) $0 \leq c \leq \gamma_{n} \leq d<1$;

(d) $0<e \leq r_{n} \leq f<1-k_{\alpha}$ and $0<e^{\prime} \leq s_{n} \leq f^{\prime}<1-k_{\beta}$.

Then the sequence $\left\{x_{n}\right\}$ converges strongly to some point $\bar{x}$, where $\bar{x}=P_{\mp} x_{1}$. 


\section{Acknowledgment}

This work was supported by a National Research Foundation of Korea Grant funded by the Korean Government (2009-0076898).

\section{References}

[1] F. E. Browder and W. V. Petryshyn, "Construction of fixed points of nonlinear mappings in Hilbert space," Journal of Mathematical Analysis and Applications, vol. 20, pp. 197-228, 1967.

[2] E. Blum and W. Oettli, "From optimization and variational inequalities to equilibrium problems," The Mathematics Student, vol. 63, no. 1-4, pp. 123-145, 1994.

[3] P. L. Combettes and S. A. Hirstoaga, "Equilibrium programming in Hilbert spaces," Journal of Nonlinear and Convex Analysis, vol. 6, no. 1, pp. 117-136, 2005.

[4] L.-C. Ceng, S. Al-Homidan, Q. H. Ansari, and J.-C. Yao, “An iterative scheme for equilibrium problems and fixed point problems of strict pseudo-contraction mappings," Journal of Computational and Applied Mathematics, vol. 223, no. 2, pp. 967-974, 2009.

[5] V. Colao, G. Marino, and H.-K. Xu, "An iterative method for finding common solutions of equilibrium and fixed point problems," Journal of Mathematical Analysis and Applications, vol. 344, no. 1, pp. 340 352, 2008.

[6] S.-S. Chang, H. W. Joseph Lee, and C. K. Chan, "A new method for solving equilibrium problem fixed point problem and variational inequality problem with application to optimization," Nonlinear Analysis: Theory, Methods \& Applications.and Methods, vol. 70, no. 9, pp. 3307-3319, 2009.

[7] Y. J. Cho, X. Qin, and J. I. Kang, "Convergence theorems based on hybrid methods for generalized equilibrium problems and fixed point problems," Nonlinear Analysis: Theory, Methods E Applications, vol. 71, no. 9, pp. 4203-4214, 2009.

[8] C. Jaiboon, W. Chantarangsi, and P. Kumam, "A convergence theorem based on a hybrid relaxed extragradient method for generalized equilibrium problems and fixed point problems of a finite family of nonexpansive mappings," Nonlinear Analysis: Hybrid Systems, vol. 4, no. 1, pp. 199-215, 2010.

[9] P. Kumam, "A hybrid approximation method for equilibrium and fixed point problems for a monotone mapping and a nonexpansive mapping," Nonlinear Analysis. Hybrid Systems, vol. 2, no. 4, pp. 1245-1255, 2008.

[10] A. Moudafi, "Weak convergence theorems for nonexpansive mappings and equilibrium problems," Journal of Nonlinear and Convex Analysis, vol. 9, no. 1, pp. 37-43, 2008.

[11] S. Plubtieng and R. Punpaeng, "A new iterative method for equilibrium problems and fixed point problems of nonexpansive mappings and monotone mappings," Applied Mathematics and Computation, vol. 197, no. 2, pp. 548-558, 2008

[12] X. Qin, M. Shang, and Y. Su, "Strong convergence of a general iterative algorithm for equilibrium problems and variational inequality problems," Mathematical and Computer Modelling, vol. 48, no. 7-8, pp. 1033-1046, 2008.

[13] X. Qin, S. M. Kang, and Y. J. Cho, "Convergence theorems on generalized equilibrium problems and fixed point problems with applications," Proceedings of the Estonian Academy of Sciences, vol. 58, no. 3, pp. 170-183, 2009.

[14] X. Qin, Y. J. Cho, and S. M. Kang, "Convergence theorems of common elements for equilibrium problems and fixed point problems in Banach spaces," Journal of Computational and Applied Mathematics, vol. 225, no. 1, pp. 20-30, 2009.

[15] S. Takahashi and W. Takahashi, "Viscosity approximation methods for equilibrium problems and fixed point problems in Hilbert spaces," Journal of Mathematical Analysis and Applications, vol. 331, no. 1 , pp. 506-515, 2007.

[16] S. Takahashi and W. Takahashi, "Strong convergence theorem for a generalized equilibrium problem and a nonexpansive mapping in a Hilbert space," Nonlinear Analysis: Theory, Methods E Applications, vol. 69, no. 3, pp. 1025-1033, 2008.

[17] A. Tada and W. Takahashi, "Weak and strong convergence theorems for a nonexpansive mapping and an equilibrium problem," Journal of Optimization Theory and Applications, vol. 133, no. 3, pp. 359-370, 2007. 
[18] W. Takahashi, Y. Takeuchi, and R. Kubota, "Strong convergence theorems by hybrid methods for families of nonexpansive mappings in Hilbert spaces," Journal of Mathematical Analysis and Applications, vol. 341, no. 1, pp. 276-286, 2008.

[19] G. Marino and H.-K. Xu, "Weak and strong convergence theorems for strict pseudo-contractions in Hilbert spaces," Journal of Mathematical Analysis and Applications, vol. 329, no. 1, pp. 336-346, 2007. 